\title{
Translational Regulation of the N-Methyl-D-Aspartate Receptor Subunit NR1
}

\author{
Rema Vazhappillya Nikolaus J. Sucher ${ }^{b}$ \\ ${ }^{a}$ Ageing and Health Section, School of Nursing, Hong Kong Polytechnic University, and \\ bMolecular Neuroscience Center, Biotechnology Research Institute and Department of Biology, \\ Hong Kong University of Science and Technology, Kowloon, Hong Kong, SAR, China
}

\section{Key Words}

N-Methyl- $D$-aspartate receptor $\cdot$ PC12 .

Posttranscriptional regulation - Translational regulation . RNA · 3'UTR · Untranslated region

\begin{abstract}
Formation of functional $\mathrm{N}$-methyl- $D$-aspartate (NMDA) receptor channels requires the essential NMDA receptor subunit NR1 and one or more of the modulatory subunits NR2A-D and in some cases an additional subunit NR3A or NR3B. Recent studies indicate that NR1 expression is regulated at translation under both physiological and pathological conditions. The rat pheochromocytoma cell line (PC12) has been used as a model system for NR1 gene expression studies. Characterization of the posttranscriptional regulatory mechanisms suggested the posttranslational degradation and translational regulation of NR1 protein in PC12 cells. In addition a recent study on the translational regulation of NR1 mRNA in intact brain identified two translationally distinct pools of NR1 mRNA. In this review we summarize the evidence for translational regulation of NR1 expression in PC12 cells and the brain.
\end{abstract}

Copyright $\odot 2004$ S. Karger AG, Basel

\section{Introduction}

N-Methyl- $D$-aspartate receptors (NMDARs) are a subset of ionotropic glutamate receptors that require the binding of both glutamate and glycine for activation [1]. In addition to their traditional role in mediating fast excitatory neurotransmission, NMDARs contribute to the regulation of neuronal gene expression and play key roles in the formation of neural networks during brain development and the formation of long-lasting memory in the adult brain. On the other hand, both NMDAR hypo- and hyperfunction are thought to contribute to the pathophysiology of a variety of neurological and psychiatric diseases [2, 3].

The formation of functional NMDARs requires an essential NR1 subunit, one or more NR2 subunits (NR2A-D) and in some cases additional NR3 subunits (NR3A, B) [1]. NMDARs in turn associate with additional proteins to form a large, dynamic, postsynaptic receptor complex [4]. Interestingly, the NR1 subunit contains the binding site for the coagonist glycine, while the NR2 subunits provide the glutamate binding sites. Recent studies indicate that association of NR1 with the two additional subunits NR3A or NR3B form glutamate-insensitive excitatory glycine receptors in recombinant expression systems [5].

The assembly of functional NMDARs, their subcellular location and the formation of the large NMDAR-signaling complex are highly regulated [6-12]. It has recently been shown that solitary NMDAR subunits are retained in the endoplasmic reticulum and rapidly degraded [13,

Dr. Nikolaus J. Sucher

Del E. Webb Center for Neurosciences and Aging

The Burnham Institute, 10901 North Torrey Pines Road

La Jolla, CA 92037 (USA)

Tel. +1 858646 3100, ext. 3762, Fax +1 858713 6273, E-Mail sucher@burnham.org 
14]. These recent results highlight the importance of posttranscriptional mechanisms in the regulation of NMDARs.

The lack of functional NMDARs in the rat pheochromocytoma cell line PC12 and the fact that these cells expressed only little NR1 protein despite the presence of NR1 and NR2 mRNAs presented the first evidence of posttranscriptional regulation of the expression of NMDARs $[15,16]$. A discrepancy between the expression of NR1 mRNA and protein has now been observed in primary neuronal cultures and a number of physiological and pathophysiological states in the brain [17-21]. The finding that the transcription of NR1 mRNA does not appear to be subject to stringent transcriptional regulation and that the NR1 promoter appears to possess the features of a housekeeping gene is consistent with the notion that the discordance between NR1 mRNA and protein expression is under posttranscriptional control [22, 23].

In this review we summarize the evidence for translational regulation of NR1 expression in PC12 cells and the brain. Potential molecular mechanisms underlying this type of control of NMDA receptor expression and evidence of translational regulation of NR2 subunits are reviewed in the paper by VanDongen and VanDongen [24] in this volume. Intracellular trafficking of NMDA receptors is reviewed by Perez-Otaño and Ehlers [25]. The transcriptional regulation of NMDARs was reviewed previously by Dingledine et al. [1].

\section{Posttranscriptional Regulation of NR1 Protein Expression in PC12 Cells}

PC12 cells contain on average about 230 copies of NR1 mRNA molecules but only 50 molecules of NR1 protein $[16,26]$. Comparing the NR1 mRNA and protein levels in PC12 cells with those in the brain, we found that the developing rat brain contained an average of 2- to 6fold more NR1 protein per $100 \mathrm{pg}$ of NR1 mRNA than PC12 cells [26].

In order to investigate whether the low levels of NR1 protein in PC12 cells were due to its rapid degradation, we performed an analysis of the turnover of NR1 protein in this cell line. We observed indeed that almost $80 \%$ of the total NR1 protein was rapidly degraded with a halflive of $1.6 \mathrm{~h}$ [26]. In addition, we found that most of the NR1 protein in PC12 cells was an immature form that was retained in the endoplasmic reticulum [26]. Adenovirus-mediated transfer of NR2 subunits resulted in the formation of functional heteromeric NMDA receptors in
PC12 cells and an increase in endogenous NR1 protein with no detectable change in NR1 mRNA levels [27]. Together, these data indicate that the lack of sufficient NR2 subunits leads to the posttranslational degradation of unassembled NR1 protein in PC12 cells.

A number of studies in primary neuronal cultures, such as hippocampal neurons [28] and cerebellar granule cells [29], indicate that posttranslational regulation of NR1 expression does occur in neurons as well as in PC12 cells. In both hippocampal neurons and cerebellar granule cells, NR1 protein is present in intracellular and surface compartments [28, 29]. In cerebellar granule cells the intracellular pool of NR1 was found to have a shorter half-life than the surface pool [29]. Furthermore, the intracellular pool consisting of unassembled NR1 was retained in the endoplasmic reticulum and destined for degradation [29]. Unlike the intracellular pool, the surface pool of NR1 consisted of NR1 subunits that were coassembled with NR2 subunits [29].

Degradation of unassembled NR1 subunits, however, proved not to be the only reason for the very low steady state level of NR1 protein in PC12 cells.

Investigations of the translational activity of NR1 mRNA in PC12 cells revealed that its translation appears to be inhibited at initiation [30]. Reporter gene expression studies further revealed that the $3^{\prime} \mathrm{UTR}$ of NR1 exerts a significant inhibitory effect on the translation in PC12 cells [30]. The comparison of the $3^{\prime} \mathrm{UTR}$ sequences of NR1 in rat, mouse and human showed high sequence conservation of a 420-bp segment [30]. This conserved stretch of sequence is capable of forming a secondary structure with a free energy of $-16.5 \mathrm{kcal} / \mathrm{mol}$. In PC12 cells this stretch of conserved 3'UTR sequence significantly inhibited translation in PC12 but not human embryonic kidney (HEK) 293 cells [30]. These data suggest that as yet unidentified cellular factors may regulate NR1 mRNA translation by binding to this conserved stretch of secondary structure in the NR1 3'UTR sequence. As the 3'UTR conserved sequence that caused the inhibition of NR1 mRNA translation is common to all splice variants, all NR1 isoforms may be subject to this form of translational regulation [30].

The NR1 mRNAs from rat and human also share a 46-bp sequence at the 5'UTR that is capable of forming a stem loop structure with a free energy of $-9.0 \mathrm{kcal} / \mathrm{mol}$ $[31,32]$. The NR1 mRNA also contains 2 transcription start sites at -276 and at -238 bp upstream of the translation start site. In PC12 cells, transcription starts at the upstream -276 site and the resulting NR1 mRNA therefore includes the conserved 46-bp sequence at the $5^{\prime} \mathrm{UTR}$ 
[23]. Reporter gene expression studies, however, failed to show an inhibitory effect of the 5'UTR on NR1 mRNA translation in PC12 cells.

In contrast, unexpectedly, the presence of the NR1 5'UTR sequence appeared to reduce the inhibition produced by the 3'UTR sequence. In accordance with our results, the NR1 5'UTR did not inhibit the mRNA translation in the Xenopus oocyte and rabbit reticulocyte translation systems [33].

\section{Translational Regulation of NR1 Protein Expression in the Brain}

Motivated by the discovery of evidence for translational regulation of NR1 expression in PC12 cells, we evaluated the translational control of NR1 mRNA in the developing and mature rat brain. A comparison of the steadystate levels of NR1 mRNA and protein during brain development revealed a progressive increase in NR1 protein expression during rat brain development [26]. Therefore, we performed an analysis of the association of mRNA with ribosomes in order to assess directly the translational activity of NR1 mRNA [34].

The results of this analysis revealed the presence of two, translationally distinct pools of NR1 mRNA in the rat brain. One pool of NR1 mRNA was associated with large polyribosomes (polysomes) at all stages of postnatal brain development. A second NR1 mRNA pool corresponding to approximately half of the NR1 mRNA at postnatal day $4(\mathrm{P} 4)$ was translationally blocked during early brain development. At P4, both NR1 mRNA pools were distributed throughout the brain. After P8, the translationally blocked NR1 mRNA pool became progressively active although brain translational activity decreased overall [35].

It is possible that the translationally blocked pool of NR1 mRNA corresponds to a 'rapid response' pool that can be activated for translation depending on the physiological requirements of the cell. Thus, NR1 protein expression may be subject to two levels of control: (1) posttranslational degradation of unassembled NR1 protein and (2) regulation of NR1 mRNA translation. Both of these regulatory mechanisms may in turn be controlled by the regulation of expression or the synthesis of NR2 and/ or NR3 subunits. In fact, NR2 subunit expression is subject to both temporal and spatial regulation during brain development [33, 36-39].

Alternatively, the translationally blocked pool of NR1 mRNA in brain may represent a pool that is in transit to dendrites. Localized protein synthesis in dendrites as a requirement for synaptic plasticity has been reported [40]. The involvement of NMDARs in activity-dependent synaptic plasticity is well established [41]. Translocation of NR1 mRNA and the regulation of the NR1 protein expression in dendrites have been demonstrated [42]. Regulation of their translation may be necessary at the early developmental period for the intense synaptic reorganization [35].

The underlying mechanisms involved in the translational regulation of the blocked pool of NR1 mRNA in brain have not been established. Translational inhibition of NR1 mRNA by its $3^{\prime}$ UTR and its association with the cytoskeleton has been demonstrated in PC12 cells. Similarly, in brain, NR1 mRNA has been found to be associated with the cytoskeleton [35]. Cytoskeletal proteins have been reported to bind specifically to $3^{\prime} \mathrm{UTR}[43,44]$. Therefore, the conserved secondary structure of the NR 1 3'UTR may serve dual functions such as stabilization and translational regulation of the NR1 mRNA in brain.

\section{Conclusions}

Both the translational regulation of NR1 mRNA and posttranslational degradation of NR1 protein contribute to the regulation of NR1 subunit expression during brain development. Characterization of molecular mechanisms underlying the NMDAR expression and function will be helpful to determine how neurons respond to developmental, environmental and pathological stimuli. The translational regulation of NR1, the essential subunit of NMDARs, may play a role in NMDAR-associated physiological functions such as the establishment of cortical circuits and synaptic plasticity underlying learning and memory as well as pathophysiological processes underlying cognitive decline and neurodegenerative and psychiatric disorders. A deficit in NMDA receptor activity is believed to be involved in the pathophysiology of psychotic symptoms in schizophrenia [45]. Unraveling the translational and posttranslational regulatory mechanisms of NR1 expression may identify novel targets for the development of drugs for the treatment of NMDAR-related diseases such as schizophrenia and depression.

\section{Acknowledgments}

This work was supported by the Hong Kong Research Grants Council.

\footnotetext{
$\overline{\text { Neurosignals 2004;13:190-193 }}$
} 


\section{References}

1 Dingledine R, Borges K, Bowie D, Traynelis S: The glutamate receptor ion channels. Pharmacol Rev 1999;51:7-60.

2 Lipton S, Rosenberg P: Excitatory amino acids as a final common pathway for neurologic disorders. N Engl J Med 1994;330:613-622.

3 Tsai G, Coyle JT: Glutamatergic mechanisms in schizophrenia. Annu Rev Pharmacol Toxicol 2002; 42:165-179.

4 Husi H, Ward MA, Choudhary JS, Blackstock WP, Grant SG: Proteomic analysis of NMDA receptor-adhesion protein signaling complexes. Nat Neurosci 2000;3:661-669.

5 Chatterton JE, Awobuluyi M, Premkumar LS, Takahashi H, Talantova M, Shin Y, Cui J, et al: Excitatory glycine receptors containing the NR3 family of NMDA receptor subunits. Nature 2002;415:793-798.

6 Rao A, Craig AM: Activity regulates the synaptic localization of the NMDA receptor in hippocampal neurons. Neuron 1997;19:801-812.

7 Tovar KR, Westbrook GL: The incorporation of NMDA receptors with a distinct subunit composition at nascent hippocampal synapses in vitro. J Neurosci 1999;19:4180-4188.

8 Barria A, Malinow R: Subunit-specific NMDA receptor trafficking to synapses. Neuron 2002; 35:345-353.

9 Fong DK, Rao A, Crump FT, Craig AM: Rapid synaptic remodeling by protein kinase $\mathrm{C}$ : Reciprocal translocation of NMDA receptors and calcium/calmodulin-dependent kinase II. J Neurosci 2002;22:2153-2164.

10 Prybylowski K, Fu Z, Losi G, Hawkins LM, Luo J, Chang K, Wenthold RJ, Vicini S: Relationship between availability of NMDA receptor subunits and their expression at the synapse. J Neurosci 2002;22:8902-8910.

11 Tovar KR, Westbrook GL: Mobile NMDA receptors at hippocampal synapses. Neuron 2002;34:255-264.

12 Wenthold RJ, Prybylowski K, Standley S, Sans N, Petralia RS: Trafficking of NMDA receptors. Annu Rev Pharmacol Toxicol 2003;43: 335-358.

13 Perez-Otano I, Schulteis C, Contractor A, Lipton SA, Trimmer J, Sucher N, Heinemann S: Assembly with the NR1 subunit is required for surface expression of NR3A-containing receptors. J Neurosci 2001;21:1228-1237.

14 Fukaya M, Kato A, Lovett C, Tonegawa S, Watanabe M: Retention of NMDA receptor NR2 subunits in the lumen of endoplasmic reticulum in targeted NR1 knockout mice. Proc Natl Acad Sci USA 2003;100:48554860

15 Leclerc CL, Chi CL, Awobuluyi M, Sucher NJ Expression of $\mathrm{N}$-methyl- $D$-aspartate receptor subunit mRNAs in the rat pheochromocytoma cell line PC12. Neurosci Lett 1995;201:103 106.
16 Sucher NJ, Brose N, Deitcher DL, Awobuluyi M, Gasic GP, Bading H, Cepko CL, Greenberg ME, Jahn R, Heinemann SF, et al: Expression of endogenous NMDAR 1 transcripts without receptor protein suggests post-transcriptional control in PC12 cells. J Biol Chem 1993;268: 22299-22304.

17 Resink A, Villa M, Benke D, Mohler H, Balazs $\mathrm{R}$ : Regulation of the expression of NMDA receptor subunits in rat cerebellar granule cells: Effect of chronic $\mathrm{K}(+)$-induced depolarization and NMDA exposure. J Neurochem 1995;64: 558-565.

18 Resink A, Villa M, Boer GJ, Mohler H, Balazs R: Agonist-induced downregulation of NMDA receptors in cerebellar granule cells in culture. Eur J Neurosci 1995; 7:1700-1706.

19 Follesa P, Ticku M: NMDA receptor upregulation: Molecular studies in cultured mouse cortical neurons after chronic antagonist exposure. J Neurosci 1996;16:2172-2178.

20 Gazzaley AH, Weiland NG, McEwen BS, Morrison JH: Differential regulation of NMDAR1 mRNA and protein by estradiol in the rat hippocampus. J Neurosci 1996;16:6830-6838.

21 Que M, Schiene K, Witte O, Zilles K: Widespread up-regulation of $\mathrm{N}$-methyl- $D$-aspartate receptors after focal photothrombotic lesion in rat brain. Neurosci Lett 1999;273:77-80.

22 Bai G, Kusiak JW: Cloning and analysis of the 5 ' flanking sequence of the rat N-methyl- $D$ aspartate receptor 1 (NMDAR1) gene. Biochim Biophys Acta 1993;1152:197-200.

23 Bai G, Kusiak JW: Functional analysis of the proximal 5'-flanking region of the N-methyl- $D$ aspartate receptor subunit gene, NMDAR1. J Biol Chem 1995;270:7737-7744.

24 VanDongen AMJ, VanDongen HMA: Effects of mRNA untranslated regions on translational efficiency of NMDA receptor subunits. Neurosignals 2004;13:194-206.

25 Pérez-Otaño I, Ehlers MD: Learning from NMDA receptor trafficking: Clues to the development and maturation of glutamatergic synapses. Neurosignals 2004;13:175-189.

26 Vazhappilly R, Sucher NJ: Turnover analysis of N-methyl- $D$-aspartate receptor subunit NR1 protein in PC12 cells. Neurosci Lett 2002;318: 153-157.

27 Satio Y, Tsuzuki K, Yamada N, Okado $\mathrm{H}$, Miwa A, Goto F, Ozawa S: Transfer of NMDAR2 cDNAs increases endogenous NMDAR1 protein and induces expression of functional NMDA receptors in PC12 cells. Brain Res Mol Brain Res 2003;110/2:159168.

28 Hall RA, Soderlings TR: Differential surface expression and phosphorylation of the $\mathrm{N}$-methyl- $D$-aspartate receptor subunits, NR1, in cultured hippocampal neurons. J Biol Chem 1997; 272:4135-4140.

29 Huh KH, Wenthold RJ: Turnover analysis of glutamate receptors identifies a rapidly degraded pool of the $\mathrm{N}$-methyl- $D$-aspartate receptor subunit, NR1, in cultured cerebellar granule cells. J Biol Chem 1999;274:151-157.
30 Awobuluyi M, Vazhappilly R, Sucher NJ: Translational activity of N-methyl- $D$-aspartate (NMDA) receptor subunit NR1 mRNA in PC12 cells. Neurosignals 2003;12/6:283-291.

31 Kozak M: An analysis of vertebrate mRNA sequences: Intimations of translational control. J Cell Biol 1991;115:887-903.

32 Kozak MA: Structural features in eukaryotic $m R N A s$ that modulate the initiation of translation. J Biol Chem 1991;266:19867-19870.

33 Wood MW, Vandongen HMA, Vandongen AMJ: The 5'-untranslated region of the $\mathrm{N}$ methyl- $D$-aspartate receptor NR2A subunit controls efficiency of translation. J Biol Chem 1996;271:8115-8120

34 Ruan H, Brown CY, Morris DR: Analysis of ribosome loading onto mRNA species: Implications for translational control; in Richter JD (ed): mRNA Formation and Function. New York, Academic Press, 1997, pp 305-340.

35 Awobuluyi M, Lipton SA, Sucher NJ: Translationally distinct populations of NMDA receptor subunit NR1 mRNA in the developing rat brain. J Neurochem 2003;87:1066-1075.

36 Petralia RS, Wang YX, Wenthold RJ: The NMDA receptor subunits NR2A and NR2B show histological and ultrastructural localization patterns similar to those of NR1. J Neurosci 1994; 14:6102-6120.

37 Williams K, Russell SL, Shen YM, Molinoff PB: Developmental switch in the expression of NMDA receptors occurs in vivo and in vitro. Neuron 1993;10:267-278.

38 Monyer H, Burnashev N, Laurie DJ, Sakmann B, Seeburg PH: Developmental and regional expression in the rat brain and functional properties of four NMDA receptors. Neuron 1994 12:529-540.

39 Sheng M, Cummings J, Roldan LA, Jan YN, Jan LY: Changing subunit composition of heteromeric NMDA receptors during development of rat cortex. Nature 1994;368:144-147.

40 Steward O, Schuman EM: Protein synthesis at synaptic sites on dendrites. Annu Rev Neurosci 2001;24:299-325.

41 Shatz CJ: Impulse activity and the patterning of connections during CNS development. Neuron 1990;5:745-756.

42 Gazzaley AH, Benson DL, Huntley GW, Morrison JH: Differential subcellular regulation of NMDAR1 protein and mRNA in dendrites of dentate gyrus granule cells after perforant path transection. J Neurosci 1997;17:2006-2017.

43 Hesketh J: Translation and the cytoskeleton: A mechanism for targeted protein synthesis. Mol Biol Rep 1994; 19:233-243.

44 St Johnston D: The intracellular localization of messenger RNAs. Cell 1995;81:161-170.

45 Akbarian S, Sucher N, Bradley D, Tafazolli A, Trinh D, Hetrick W, Potkin S, Sandman C, Bunney W Jr, Jones E: Selective alterations in gene expression for NMDA receptor subunits in prefrontal cortex of schizophrenics. $\mathrm{J}$ Neurosci 1996;16:19-30. 